\title{
Bactérias gram-negativas em cardeais (Paroaria coronata e Paroaria dominicana) apreendidos do tráfico de animais silvestres
}

\author{
Gram-negative bacterium isolated from cardinals (Paroaria coronata and P. dominicana) seized \\ from illegal wildlife trade
}

\author{
Marcos Paulo Vieira CUNHA ${ }^{1}$; Marta Brito GUIMARÃES ${ }^{1}$; Yamê Miniero DAVIES ${ }^{1}$; Liliane MILANELO²; \\ Terezinha KNÖBL ${ }^{1}$
}

\footnotetext{
${ }^{1}$ Universidade de São Paulo, Faculdade de Medicina Veterinária e Zootecnia, Departamento de Patologia, São Paulo - SP, Brasil

${ }^{2}$ Departamento de Águas e Energia Elétrica, Centro de Recuperação de Animais Selvagens, Parque Ecológico do Tietê, São Paulo - SP, Brasil
}

\begin{abstract}
Resumo
Anualmente o tráfico de animais silvestres retira milhões de aves da natureza. Os cardeais (Paroaria coronata) e cardeais-donordeste (Paroaria dominicana) estão incluídos entre as espécies de aves mais traficadas. A microbiota cloacal de passeriformes de vida livre é composta principalmente por bacilos e cocos gram-positivos, já os bacilos gram-negativos predominam em aves de cativeiro. Em situações de estresse e baixa de imunidade as bactérias gram-negativas podem causar infecções oportunistas. $\mathrm{O}$ presente trabalho identificou bactérias da microbiota da cloaca de 49 espécimes de $P$. coronata e $P$. dominicana apreendidas do tráfico de animais silvestres em São Paulo (SP). Foram isoladas treze espécies de bactérias gram-negativas, incluindo Salmonella spp. e Pseudomonas aeruginosa. A maior frequência de ocorrência foi de Escherichia coli, identificada em 42/49 $(85,7 \%)$ das amostras fecais. Dentre os isolados de E. coli, $21 / 42$ pertenciam aos grupos filogenéticos B2 e D, relacionados a estirpes patogênicas que causam doença extraintestinal em humanos. Klebsiella pneumoniae foi isolada em 28/49 (57,1\%) das amostras. Esses resultados reforçam que as condições estressantes a que esses animais são submetidos em situações de tráfico, incluindo o contato com humanos, podem favorecer a colonização da microbiota cloacal das aves por patógenos, o que representa um risco para a sua reintrodução na natureza considerando-se o possível contato com humanos e outros animais.
\end{abstract}

Palavras-chave: Tráfico de animais. Enterobactérias. Paroaria sp.. Escherichia coli. Salmonella.

\begin{abstract}
Illegal wildlife trade removes millions of birds from nature every year. Among the most trafficked species of birds are redcrested cardinals (Paroaria coronata) and red-cowled cardinals (Paroaria dominicana). The cloacal microbiota of free-living passerines consists mainly of gram-positive bacilli and cocci, and gram-negative bacilli predominate in captive birds. Under stress and low immunity, gram-negative species may cause opportunistic infections. This study identified bacteria from cloacal microbiota of 49 specimens of $P$. coronata and $P$. dominicana seized from illegal wildlife trade in São Paulo (SP). In this study, 13 species of gram-negative bacteria, including Salmonella spp. and Pseudomonas aeruginosa were isolated. An increased occurrence of Escherichia coli was identified in 42/49 (85.7 \%) of fecal samples. Among the E. coli strains, 21/42 belonging to the phylogenetic groups $\mathrm{B} 2$ and $\mathrm{D}$, were related to extraintestinal pathogenic strains causing disease in humans. Klebsiella pneumoniae were isolated in 28/49 (57.1\%) samples. These results reinforce the fact that stressful conditions of illegal trade can favor the colonization of cloacal microbiota of these birds by pathogens, which represents a risk for their reintroduction into the wild, including the transmission of diseases to humans and other animals.
\end{abstract}

Keywords: Wildlife illegal trade. Enterobacteria. Paroaria sp.. Escherichia coli. Salmonella. 
Correspondência para:

Marcos Paulo Vieira Cunha

Universidade de São Paulo, Faculdade de Medicina

Veterinária e Zootecnia, Departamento de Patologia

Av. Prof. Orlando Marques de Paiva, 87

CEP 05508-270, São Paulo, SP, Brasil

e-mail: marcospvc@usp.br

Recebido: 07/01/2015

Aprovado: 06/02/2016

O tráfico de animais silvestres é uma atividade ilegal que movimenta bilhões de espécimes vivos, assim como produtos obtidos desses animais, anualmente em todo mundo (SMITH et al., 2009). No Brasil, são escassos os dados numéricos sobre os danos que esta atividade representa. Estima-se a retirada de 38 milhões de espécimes da natureza anualmente, movimentando cerca de 2,5 bilhões de dólares somente no país (REDE NACIONAL DE COMBATE AO TRÁFICO DE ANIMAIS SILVESTRES, RENCTAS, 2001).

Dentre todos os animais envolvidos, as aves são a classe mais traficada. Estimativas apontam para a retirada de mais de 400 espécies de aves, o que representa $23 \%$ das espécies de aves nativas no Brasil (ALVES et al., 2013b).

Em virtude da beleza do canto e plumagem, as espécies da ordem Passeriformes são as mais afetadas pelo tráfico, visto que nove em cada dez pássaros apreendidos pertencem a esta ordem (GODOY; MATUSHIMA, 2010). Em vários estudos o gênero Paroaria é o principal passeriforme traficado, particularmente as espécies Paroaria coronata (cardeal, cardeal do sul) e Paroaria dominicana (cardeal do nordeste, galo-da-campina) (RENCTAS, 2001; PAGANO et al., 2009; GODOY; MATUSHIMA, 2010; REGUEIRA; BERNARD, 2012; ALVES et al., 2013a; LICARIÃO et al., 2013).

Além da ameaça ao futuro das espécies e ao equilíbrio da biodiversidade pela diminuição do número de indivíduos na natureza, o tráfico contribui para a introdução de espécies em novas regiões, o que leva à competição por alimento com espécies endêmicas, alterando ecossistemas ou destruindo culturas e lavouras (SMITH et al., 2009). A reintrodução de aves traficadas na natureza pode carrear patógenos que representam uma ameaça à biodiversidade, à saúde pública e a produção agrícola (SMITH et al., 2009). No Brasil, estima-se que 78\% dos animais apreendidos sejam devolvidos à natureza sem critérios sanitários (GODOY; MATUSHIMA, 2010).

O papel dos pássaros na transmissão de doenças é subestimado, visto que essas aves podem albergar patógenos primários ou oportunistas (BENSKIN et al., 2009). Apesar de existirem poucos dados sobre o assunto, tem sido observado que a microbiota entérica de passeriformes em vida livre é composta principalmente por bacilos e cocos gram-positivos (GLÜNDER, 1981; HARRISON; MCDONALD, 2006). Em contraste, a colonização do trato gastrintestinal por bactérias gram-negativas é mais comum quando as aves estão em cativeiro (BENSKIN et al., 2009).

O objetivo do presente trabalho foi isolar e identificar bacilos gram-negativos presentes na microbiota cloacal de cardeais apreendidos do tráfico de animais silvestres em São Paulo, SP.

Foram avaliados 30 espécimes de Paroaria dominicana e 19 espécimes de Paroaria coronata, de qualquer idade e sexo, apreendidos em 2014, pelo Instituto Brasileiro do Meio Ambiente e dos Recursos Renováveis (IBAMA), polícia florestal e bombeiros. Esses animais foram mantidos no Centro de Recuperação de Animais Silvestres do Parque Ecológico do Tietê - núcleo Engenheiro Goulart (CRAS/PET), localizado a $23^{\circ} 25^{\prime} \mathrm{S}$ e $46^{\circ} 28^{\prime} \mathrm{W}$, e administrado pelo Departamento de Águas e Energia do Estado de São Paulo (DAEE), Licença SISBIO: 42431-1 e aprovado pela Comissão de Ética no Uso de Animais da Faculdade de Medicina Veterinária e Zootecnia da Universidade de São Paulo, protocolado sob o CEUA n⿳0 6876261114.

Foram coletadas amostras de fezes e suabes de cloaca das 49 aves. O material foi encaminhado para o Laboratório de Medicina Aviaria do Departamento 
de Patologia da Faculdade de Medicina Veterinária e Zootecnia da USP visando o cultivo e isolamento microbiológico. Todas as amostras fecais foram semeadas em caldo BHI (Infusão de cérebro e coração, Dif(co ${ }^{\mathrm{Tm}}$ ) e caldo tetrationato. Ademais, foram realizados isolamento em ágar MacConkey e ágar XLT4, com incubação a $37^{\circ} \mathrm{C}$ por 24 horas, e 48 horas respectivamente. As colônias selecionadas foram identificadas por provas bioquímicas específicas (EPM, MiLi e Citrato) (KONEMAN et al., 2008).

Os isolados identificados como Salmonella spp. nos testes bioquímicos foram submetidos à técnica de multiplex PCR (ALVAREZ et al., 2004), que consiste na amplificação de genes que classificam a estirpe como Salmonella spp., Salmonella Typhimurium ou Salmonella Enteritidis. As estirpes identificadas como Escherichia coli foram submetidas à técnica descrita por Clermont et al. (2000), que consiste na amplificação de dois genes (chuA e yjaA) e de um fragmento anômalo de DNA (TSPE4.C2) que classifica $E$. coli em um dos quatro grupos filogenéticos (A, B1, B2 e D).

Amostras fecais de todas as aves apresentaram isolamento de pelo menos uma espécie de bactéria gram-negativa (Tabela 1).

Glunder (1981) investigando fezes de 98 passeriformes hígidos, não encontrou bacilos gramnegativos em $82,6 \%$ das aves examinadas, sugerindo que as enterobactérias não são faziam parte da microbiota intestinal das aves. No entanto, em pesquisas realizadas com $E$. coli isoladas de diversas espécies de aves de vida livre e cativeiro foram isoladas diferentes espécies gram-negativas exibindo um estilo de vida comensal no trato gastrintestinal dos animais (MATTES et al., 2005; XENOULIS et al., 2010; VAN DONGEN et al., 2013). Estes estudos sugerem que mesmo as aves tratadas com manejo sanitário adequado podem atuar como portadoras assintomáticas.

Dois espécimes de $P$. dominicana foram positivos para Salmonella spp. (Tabela 1). Marietto-Gonçalves
Tabela 1 - Espécies de bactérias Gram-negativas isoladas da cloaca de $P$. coronata e $P$. dominicana

\begin{tabular}{|c|c|}
\hline Espécie de bactéria & $N(\%)$ de aves \\
\hline Escherichia coli (todos grupos filogenéticos) & $42(85,7)$ \\
\hline Escherichia coli $\mathrm{A}^{\mathrm{a}}$ & $10(20,4)$ \\
\hline Escherichia coli B1 & $11(22,4)$ \\
\hline Escherichia coli B2 & $11(22,4)$ \\
\hline Escherichia coli D & $10(20,4)$ \\
\hline Salmonella spp..$^{\mathrm{b}}$ & $2(4,0)$ \\
\hline Klebsiella pneumoniae & $28(57,1)$ \\
\hline Klebsiella oxytoca & $7(14,2)$ \\
\hline Citrobacter freundii & $13(26,5)$ \\
\hline Citrobacter diversus & $7(14,2)$ \\
\hline Enterobacter cloacae & $14(28,4)$ \\
\hline Enterobacter aerogenes & $4(8,0)$ \\
\hline Enterobacter sp..$^{c}$ & $2(4,0)$ \\
\hline Serratia liquefaciens & $9(18,3)$ \\
\hline Serratia marcenses & $4(8,0)$ \\
\hline Serratia odorifera & $1(2,0)$ \\
\hline Serratia sp. $^{\mathrm{d}}$ & $3(6,1)$ \\
\hline Proteus vulgaris & $1(2,0)$ \\
\hline Pseudomonas aeruginosa & $4(8,0)$ \\
\hline
\end{tabular}

${ }^{a}$ Grupo filogenético de E. coli

${ }^{\mathrm{b}}$ Outros sorotipos de Salmonella que não Typhimurium e Enteritidis

' Outras espécies de Enterobacter que não E. cloacae e E. aerogenes

d Outras espécies de Serratia que não $S$. liquefaciens, $S$. marcenses e $S$. odorifera

et al. (2010) isolaram Salmonella Enteritidis em três papagaios verdadeiros proveniente do tráfico de animais do estado de São Paulo. No presente estudo, apesar de nenhum dos animais amostrados apresentarem Salmonella dos sorotipos Enteritidis ou Typhimurium, os achados indicam a circulação de Salmonella em aves apreendidas do tráfico, reforçando o potencial zoonótico desses animais, devido ao contato com humanos.

Escherichia coli foi isolada de $29 P$. dominicana e $13 P$. coronata, o que indica ampla disseminação desse agente nessas aves. As estirpes de E. coli foram distribuídas quase que igualmente em todos os grupos filogenéticos (Tabela 1). Isolados classificados nos grupos A e B1 são considerados comensais, enquanto os grupos $\mathrm{D}$ e principalmente $\mathrm{B} 2$, agrupam estirpes pertencentes aos patotipos que causam doença extraintestinal, incluindo amostras APEC (Escherichia coli patogênicas para aves), UPEC (uropatogênicas) e NMEC (associadas a meningite neonatal) (MELLATA, 2013). Apesar de não 
existirem relatos de E. coli pertencente a grupos filogenéticos patogênicos isolados desse tipo de ave no Brasil, Cunha et al. (2014) reportaram que a maior parte das E. coli que causam doença respiratória em perus no país pertence ao grupo filogenético B2. Esse mesmo estudo verificou, ainda, estirpes classificadas no grupo filogenético B2 com um número maior de fatores de virulência associados em comparação com filogrupos A, B1 e D.

Klebsiella sp., Enterobacter sp. e Citrobacter sp. são patógenos pertencentes a família Enterobacteriaceae conhecidos na clínica de aves por causarem infecções respiratórias ou gastrintestinais (BENSKIN et al., 2009). Godoy e Matushima (2010) relataram infecções por esses agentes como causa de morte de passeriformes apreendidos do tráfico de animais silvestres. No presente estudo esses três

\section{Referências}

ALVAREZ, J.; SOTA, M.; VIVANCO, A. B.; PERALES, I.; CRISTERNAL, R.; REMENTERIA, A.; GARAIZAR, J. Development of a multiplex PCR technique for detection and epidemiological typing of Salmonella in human clinical samples. Journal of Clinical Microbiology, v. 42, n. $4, \quad$ p. 1734-1738, 2004. doi: http://dx.doi.org/10.1128/JCM.42.4.1734-1738.2004.

ALVES, R. R. N.; LEITE, R. C. L.; SOUTO, W. M. S.; BEZERRA, D. M. M.; LOURES-RIBEIRO, A. Ethnoornithology and conservation of wild birds in the semiarid Caatinga of northeastern Brazil. Journal of Ethnobiology and Ethnomedicine, v. 9, n. 14, p. 1-12, 2013a. doi: http://dx.doi.org/10.1186/1746-4269-9-14.

ALVES, R. R. N.; LIMA, J. R. F.; ARAUJO, H. F. P. The live bird trade in Brazil and its conservation implications: an overview. Bird Conservation International, v. 23, n. 1, p. 53-65, 2013b. doi: http://dx.doi.org/10.1017/S095927091200010X.

BENSKIN, C. M. H.; WILSON, K.; JONES, K.; HARTLEY, I. R. Bacterial pathogens in wild birds: a review of the frequency and effects of infection. Biological Reviews, v. 89, p. 349-373, 2009. doi: http://dx.doi.org/10.1111/j.1469185X.2008.00076.x. gêneros de bactérias foram os mais frequentes após E. coli.

A única espécie isolada no presente trabalho que não pertencia à família Enterobacteriaceae foi Pseudomonas aeruginosa, patógeno frequentemente isolado de infecções no trato respiratório, enterite hemorrágica, ulceras de córnea e septicemia em aves (BENSKIN et al., 2009).

Infere-se que as aves amostradas albergavam agentes entéricos como microbiota comensal. No entanto, em situações de estresse, particularmente em condições de tráfico dos animais, esses microorganismos podem causar infecções oportunistas, o que representa um risco não apenas para essas espécies animais, mas também para humanos e outros animais, assim como para a reintrodução dessas aves na natureza.

CLERMONT, O.; BONACORSI, S.; BINGEN, E. Rapid and simple determination of the Escherichia coli phylogenetic group. Applied and Environmental Microbiology, v. 66, n. 10, p. 4555-4558, 2000. doi: http://dx.doi.org/10.1128/AEM.66.10.4555-4558.2000.

CUNHA, M. P. V.; OLIVEIRA, M. G. X.; OLIVEIRA, M. C. V.; SILVA, K. C.; GOMES, C. R.; MORENO, A. M.; KNÖBL, T. Virulence profiles, phylogenetic background, and antibiotic resistance of Escherichia coli isolated from turkeys with airsacculitis. The Scientific World Journal, v. 2014, p. 1-8, 2014. doi: http://dx.doi.org/10.1155/2014/289024.

GLÜNDER, G. Ocurrence of Enterobacteriaceae in feces of granivorous passeriforme birds. Avian Diseases, v. 25, n. 1, p. 195-198, 1981. doi: http://dx.doi.org/10.2307/1589841.

GODOY, S. N.; MATUSHIMA, E. R. A survey of diseases in passeriform birds obtained from illegal wildlife trade in Sao Paulo city, Brazil. Journal of Avian Medicine and Surgery, v. 24, n. 3, p. 199-209, 2010. doi: http://dx.doi.org/10.1647/2009-029.1.

HARRISON, G. J.; MCDONALD, D. Nutritional considerations section II: nutritional disorders. In: HARRISON, G. J.; LIGHTFOOT, T. (Eds.). Clinical avian 
medicine. $1^{\text {st }}$ ed. Palm Beach, FL: Spix Publishing, 2006. p. 109-140.

KONEMAN, E. W.; WILLIAM, M. J.; SCHRECKENBERGER, P. C.; WINN, W. C.; ALLEN, S. D.; WOODS, G. L. As enterobacteriaceae. In: KONEMAN, E. W.; WILLIAM, M. J.; SCHRECKENBERGER, P. C.; WINN, W. C.; ALLEN, S. D.; WOODS, G. L. Diagnóstico microbiológico: texto e atlas colorido. Rio de Janeiro: Guanabara Koogan, 2008. p. 204-288.

LICARIÃO, M. R.; BEZERRA, D. M. M.; ALVES, R. R. N. Wild birds as pets in Campina Grande, Paraíba State, Brazil : an ethnozoological approach. Anais da Academia Brasileira de Ciências, v. 85, n. 1, p. 201-213, 2013. doi: http://dx.doi.org/10.1590/S0001-37652013000100011.

MARIETTO-GONÇALVES, G. A.; ALMEIDA, S. M.; LIMA, E. T.; OKAMOTO, A. S.; PINCZOWSKI, P.; ANDREATTI FILHO, R. L. Isolation of Salmonella enterica serovar Enteritidis in blue-fronted Amazon parrot (Amazona aestiva). Avian Diseases, v. 54, n. 1, p. 151-155, 2010. doi: http://dx.doi.org/10.1637/8906-043009-Case.1.

MATTES, B. R.; CONSIGLIO, S. A. S.; ALMEIDA, B. Z.; GUIDO, M. C.; ORSI, R. B.; COSTA, A.; FERREIRA, A. J. P.; KNÖBL, T. Influência da biossegurança na colonização intestinal por Escherichia coli em psitacídeos. Arquivos do Instituto Biológico, v. 72, n. 1, p. 13-16, 2005.

MELLATA, M. Human and avian extraintestinal pathogenic Escherichia coli: infections, zoonotic risks, and antibiotic resistance trends. Foodborne Pathogens and Disease, v. $10, \quad$ n. 11 , p. 916-932, 2013. doi: http://dx.doi.org/10.1089/fpd.2013.1533.
PAGANO, I. S. D. A.; SOUSA, A. E. B. A.; WAGNER, P. G. C.; RAMOS, R. T. C. Aves depositadas no Centro de Triagem de Animais Silvestres do IBAMA na Paraíba: uma amostra do tráfico de aves silvestres no estado. Ornithologia, v. 3, n. 2, p. 132-144, 2009.

REGUEIRA, R. F. S.; BERNARD, E. Wildlife sinks: quantifying the impact of illegal bird trade in street markets in Brazil. Biological Conservation, v. 149, n. 1, p. 16-22, 2012. doi: http://dx.doi.org/10.1016/j.biocon.2012.02.009.

REDE NACIONAL DE COMBATE AO TRÁFICO DE ANIMAIS SILVESTRES. RENCTAS. $\mathbf{1}^{\mathbf{0}}$ Relatório Nacional sobre o Tráfico de Fauna Silvestre. 2001. Disponível em: <http://www.renctas.org.br/>. Acesso em: 30 nov. 2014.

SMITH, K. F.; BEHRENS, M.; SCHLOEGEL, L. M.; MARANO, N.; BURGIEL, S.; DASZAK, P. Reducing the risks of the wildlife trade. Science, v. 324, n. 5927, p. 594595, 2009. doi: http://dx.doi.org/10.1126/science.1174460.

VAN DONGEN, W. F. D.; WHITE, J.; BRANDL, H. B.; MOODLEY, Y.; MERKLING, T.; LECLAIRE, S.; BLANCHARD, P.; DANCHIN, E.; HATCH, S. A.; WAGNER, R. H. Age-related differences in the cloacal microbiota of a wild bird species. BMC Ecology, v. 13, n. 11, p. 1-12, 2013. doi: http://dx.doi.org/10.1186/1472-6785-13-11.

XENOULIS, P. G.; GRAY, P. L.; BRIGHTSMITH, D.; PALCULICT, B.; HOPPES, S.; STEINER, J. M.; TIZARD, I.; SUCHODOLSKI, J. S. Molecular characterization of the cloacal microbiota of wild and captive parrots. Veterinary Microbiology, v. 146, n. 3-4, p. 320-325, 2010. doi: http://dx.doi.org/10.1016/j.vetmic.2010.05.024. 